\title{
Famílias políticas tradicionais nas eleições à Prefeitura de Guarapuava em 2016
}

\author{
Natália Cristina Granato ${ }^{1}$
}

- Enviado em 15/09/2016

- Aprovado em 18/09/2016
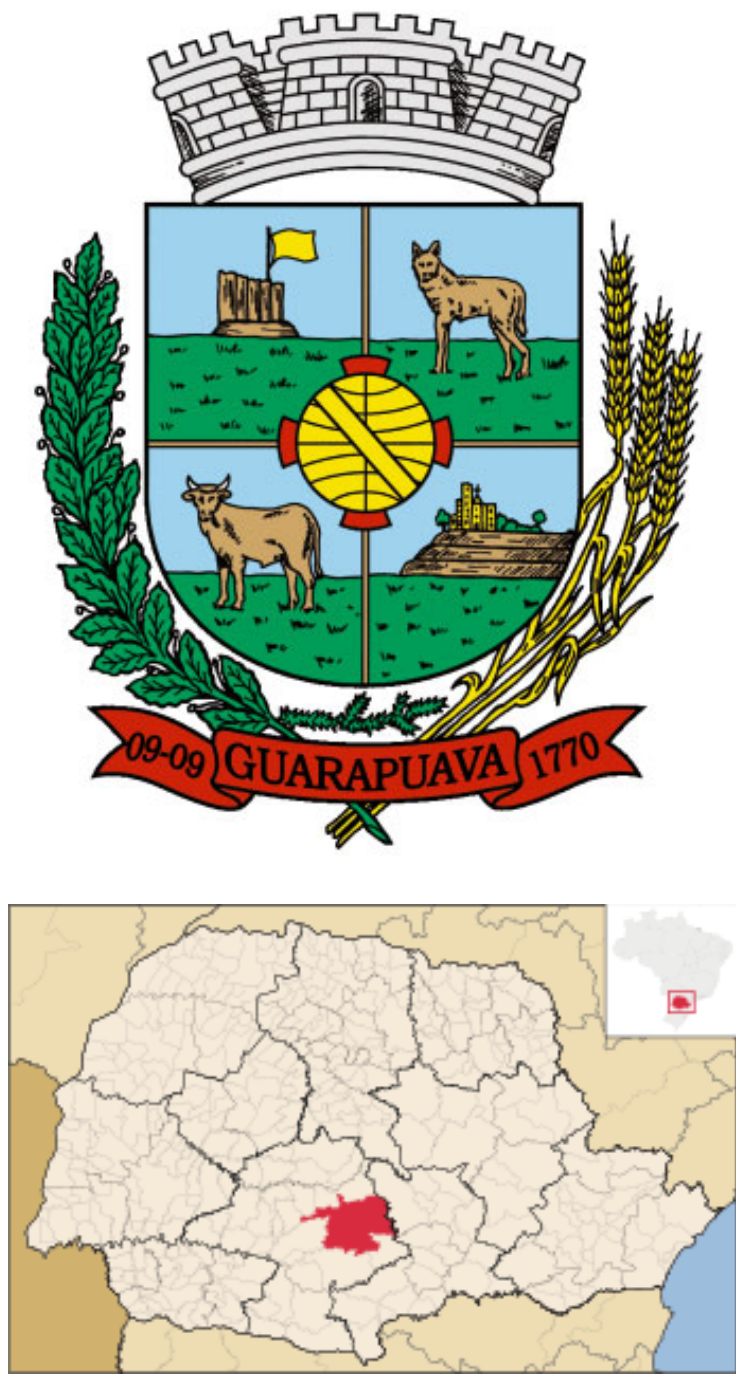

Fonte: http://www.guarapuava.pr.gov.br/turista/brasao/. Acesso 18.setembro.2016

1 Graduada em Ciências Sociais e Mestre em Sociologia pela UFPR. Endereço eletrônico: nataliagranato@hotmail.com 
Famílias políticas tradicionais nas eleições à Prefeitura de Guarapuava em 2016

\author{
Natália Cristina Granato
}

Guarapuava é um município do Paraná que possui uma população de 167.328 habitantes ${ }^{2}$, segundo o censo de 2010, localizada na região centro-sul. Nas eleições de 2016, Guarapuava contará com o voto de 119.458 eleitores na escolha de seu prefeito e seus vereadores ${ }^{3}$

Sua povoação data de 1809, ano em que o bandeirante Azevedo Portugal e sua tropa começaram a se instalar, capturar e aldear os índios que habitavam a região ${ }^{4}$. A geógrafa Márcia da Silva (2005), em sua Tese de Doutorado, categoriza Guarapuava como um "território conservador de poder", que define-se pela não-ruptura das barreiras com os valores da sociedade tradicional de origem colonial e população luso-brasileira, com características do mandonismo, oligarquismo, familismo e do personalismo, incrementadas pela concentração fundiária e a chegada tardia dos imigrantes estrangeiros. Tais características contribuíram para a perpetuação de famílias tradicionais na dominação política e econômica grarapuaviana, com destaque ao agrupamento dos Mattos Leão, dos Silvestre e dos Ribas Carli em primeiro plano, e secundariamente representados pelos Kruger e os Burko (AUGUSTO; SILVA, 2011, p.120). A ideia de poder político e econômico no Paraná é enfatizada pelas obras de Ricardo Costa de Oliveira (2000; 2004; 2012), que analisam a conexão entre o poder político e as famílias que dominam a política paranaense há séculos, desde os tempos coloniais. $\mathrm{O}$ autor argumenta que aproximadamente 50 famílias históricas do período colonial perpetuam a sua dominação ao longo dos séculos, em detrimento das

2 IBGE Cidades: Paraná: Guarapuava: Infográficos: Dados Gerais do Município. Disponível em: http://cidades.ibge.gov.br/painel/painel.php?codmun=410940

3 TRIBUNAL REGIONAL ELEITORAL DO PARANÁ. Distribuição do Eleitorado por Município/Zona. Disponível em: http://www.justicaeleitoral.jus.br/arquivos/tre-pr-elo-cadastro-eleitoral-eleitorado-ordenado-por-municipio

4 IBGE. Divisão Territorial Brasileira. Guarapuava. Disponível em: http://biblioteca.ibge.gov.br/visualizacao/dtbs/parana/guarapuava.pdf 
transformações políticas e modernização no capitalismo. Essas famílias articulam os seus poderes econômicos, políticos e culturais para a dominação (OLIVEIRA, 2000, p.2).

Nas eleições para prefeito de Guarapuava em 2016, destacamos a permanência destas relações políticas evidenciadas nas candidaturas. Podemos visualisá-las nas eleições antecessoras, de 2014, em que os deputados estaduais eleitos que representam a região são provenientes das famílias listadas por Márcia da Silva, anteriormente vistas. Começando por Artagão de Mattos Leão Júnior, até então do PMDB, eleito na $4^{0}$ colocação estadual, com $78.594 \operatorname{votos}^{5}$. Sua família está presente na política paranaense desde o século XIX. É descendente de José de Mattos Leão, que foi prefeito de Guarapuava, e João de Mattos Leão, Vereador em Guarapuava, de 1955 a 1958; Deputado Estadual pelo PSD, de 1963 a 1966; Deputado Estadual, pela ARENA, de 1967-1970; Secretário da Justiça do Paraná, de 1966 a 1969 e Senador pela ARENA, de 1971 a 1978. Artagão Júnior também é sobrinho de Aragão de Mattos Leão, deputado estadual e federal nos anos 1970 e 1980 (GRANATO, 2016, p.233) e filho de Artagão de Mattos Leão, deputado estadual eleito nos pleitos de 1982, 1986 e 1990, que deixou o cargo para se tornar conselheiro do Tribunal de Contas do Estado, cargo que ocupa até atualidade, sendo também corregedor em 1992 e 1994, além de Presidente entre 1996 e 1998 e de 2013 a 20146. Artagão Júnior foi eleito deputado estadual nas eleições de 2002, 2006, 2010 e 2014, ocupado desde março de 2016 a Secretaria de Justiça, Cidadania e Direitos Humanos, encontrando-se atualmente no PSB?

Outro deputado estadual eleito pela região de Guarapuava é Bernardo Ribas Carli, que obteve 55.481 votos (TRE-PR), pelo PSDB, cumprindo o seu segundo mandato. Filho de Fernado Ribas Carli, Prefeito de Guarapuava por três mandatos, Deputado Federal e Estadual

\footnotetext{
5 TRIBUNAL REGIONAL ELEITORAL DO PARANÁ. Estatísticas Eleitorais de 2014. Disponível em: http://www.tse.jus.br/eleicoes/estatisticas/estatisticas-candidaturas-2014/copy of estatisticas-eleitorais-2014

6 TRIBUNAL DE CONTAS DO ESTADO DO PARANÁ. História do Tribunal. Disponível em: http://www1.tce.pr.gov.br/conteudo/historia-do-tribunal/5/area/45

${ }^{7}$ Artagão Júnior saiu do PMDB após desentendimentos com Roberto Requião, indo para o PSB, juntamente com Alexandre Curi, Jonas Guimarães e Luiz Cláudio Romanelli. G1 Paraná. 15/03/2016

Deputado Artagão Júnior assume a Secretaria de Justiça do Paraná. Disponível em: http://g1.globo.com/pr/parana/noticia/2016/03/deputado-artagao-junior-assume-secretaria-de-justica-doparana.html
} 
e Chefe da Casa Civil do Governo do Estado $^{8}$, e primo do ex-deputado estadual Fernando Ribas Carli. É descendente dos primeiros povoadores de Guarapuava pelo lado da família Rocha Loures, além de possuir parentesco com as famílias Ferreira, Siqueira, Cortes e Maciel, descendentes dos bandeirantes povoadores da região (SILVA, 2005, p.21).

A deputada estadual que assumiu como suplente da região é Isabel Cristina Rauen Silvestri, do PPS. Mãe do atual prefeito de Guarapuava e candidato à reeleição, César Silvestri, Cristina é esposa de César Silvestri, vice-prefeito de Guarapuava em 1988, deputado estadual pelo PDT, eleito em 1990, Engenheiro civil do DER de Guarapuava entre 1978 e 1982. César Silvestri é, por sua vez, filho de Moacyr Júlio Silvestre, Prefeito de Guarapuava pelo PTB entre 1960 e 1962, Deputado Estadual pelo PTB entre 1963 e 1966, Deputado Federal pela ARENA, entre 1967 e 1969, novamente Prefeito de Guarapuava pela ARENA, entre 1969 e 1972.

Estas mesmas famílias que dominaram as eleições de 2014 vêm exercendo influência nas eleições de 2016. 0 candidato a reeleição pelo PPS é César Silvestri Filho, 36 anos, casado, natural de Guarapuava, filho de César e Cristina Silvestri. Foi eleito deputado estadual em 2010, prefeito de Guarapuava em 2012 e tenta a reeleição este ano, sendo apoiado por uma ampla coligação, intitulada "Força para muito mais" que abrange os seguintes partidos, segundo a divulgação de candidaturas do Tribunal Superior Eleitoral: PPS, PDT, PROS, PMB, PSC, PR, PSD, PHS, PMN, PSDC, PRB, PSL, PRB, PTB, PV, PMDB, além do importante apoio do PSB de Artagão de Mattos Leão Júnior9. Temos, portanto, duas famílias políticas (Silvestri e Mattos Leão) associadas em torno da candidatura de César Silvestri Filho. A terceira principal família política, Ribas Carli, se absteve de apoiar ou se coligar a algum dos candidatos em Guarapuava, pois seu grupo é de oposição às famílias Mattos Leão e Silvestri (AUGUSTO; SILVA, 2011, p.120). 0 deputado Estadual Bernardo Ribas Carli está apoiando candidatos do PSDB nos municípios que compõe a região, conforme divulgação de sua página no Facebook ${ }^{10}$.

Outras 3 candidaturas a prefeito foram registradas em Guarapuava, segundo a divulgação de candidaturas do Tribunal Superior Eleitoral. O candidato do PT é o médico

8 ALEP. Conheça os deputados. Bernardo Carli. Disponível em: http://www.alep.pr.gov.br/deputados/perfil/112-bernardo-carli

9 "Guarapuava não pode entrar na contramão", diz Artagão Jr. Disponível em: http://www.redesuldenoticias.com.br/noticias/05 082016 guarapuava nao pode entrar na contramao diz a rtagao jr.htm

10 Bernardo Ribas Carli. Disponível em: https://www.facebook.com/bernardocarli.oficial 
Antenor Gomes de Lima, 56 anos, casado, natural de Guarapuava, apoiado pela coligação "Guarapuava é a gente que faz", composta pelo PTC, PCdoB, PMDB, PEN e PPL. Antenor Gomes foi candidato derrotado para a prefeitura de Guarapuava nas eleições de 2012, na qual contou com o apoio de Artagão de Mattos Leão Júnior (AUGUSTO; GOMES, 2015, p.125). Antenor Gomes de Lima foi Vereador de Guarapuava entre 2001 e 2004, suplente em 2004 e novamente vereador em 2008. Em 2012, foi candidato a prefeito de Guarapuava em 2012, pelo PT (TRE-PR).

João Alberto Nieckars da Silva é o candidato da REDE. Com 34 anos, é solteiro, advogado e natural de Guarapuava.

Luciano Roszkowski, "Luciano Gago", é o candidato do PT do B, pela coligação "Nova Guarapuava”, que conta com o PTN e o SD. Com 44 anos, é casado, empresário, natural de Guarapuava.

\section{Referências}

ALEP. Conheça os deputados. Disponível em: http://www.alep.pr.gov.br/deputados/perfil/112-bernardo-carli

AUGUSTO, Daniel Cirilo; SILVA, Márcia da. "Revelando" grupos de poder político nas páginas de jornais locais. Percurso: Sociedade, Natureza e Cultura, n. 11, p. 110-126, 2010-1.

FACEBOOK. Bernardo Ribas Carli. Disponível em: https://www.facebook.com/bernardocarli.oficial

G1 PARANÁ. Deputado Artagão Júnior assume a Secretaria de Justiça do Paraná. Disponível em: $\quad$ http://g1.globo.com/pr/parana/noticia/2016/03/deputado-artagao-junior-assumesecretaria-de-justica-do-parana.html

IBGE Cidades: Paraná: Guarapuava: Infográficos: Dados Gerais do Município. Disponível em: http://cidades.ibge.gov.br/painel/painel.php?codmun=410940

IBGE. Divisão Territorial Brasileira. Guarapuava. Disponível em: http://biblioteca.ibge.gov.br/visualizacao/dtbs/parana/guarapuava.pdf

OLIVEIRA, Ricardo Costa de. 0 silêncio das genealogias: classe dominante e estado no Paraná (1853-1930). Tese. Doutorado em Ciências Sociais. Universidade Estadual de Campinas, 2000. 
OLIVEIRA, Ricardo Costa de. Famílias, Poder e Riqueza: Redes Políticas no Paraná em 2007. Sociologias, Porto Alegre, ano 9, no 18, jun./dez. 2007, p. 150-169.

OLIVEIRA, Ricardo Costa de. Na teia do nepotismo. Curitiba: Insight, 2012.

REDE SUL DE NOTÍCIAS. Guarapuava não pode entrar na contramão", diz Artagão Jr. Disponível em:

http://www.redesuldenoticias.com.br/noticias/05 082016 guarapuava nao pode entrar na contramao diz artagao jr.htm

SILVA, Márcia da. Territórios Conservadores de Poder no Centro-Sul do Paraná. Tese. Doutorado em Geografia. Universidade Estadual Paulista, Presidente Prudente, 2005. Orientador: Prof. Dr. Jayro Gonçalves Melo.

TRIBUNAL DE CONTAS DO ESTADO DO PARANÁ. História do Tribunal. Disponível em: http://www1.tce.pr.gov.br/conteudo/historia-do-tribunal/5/area/45

TRIBUNAL REGIONAL ELEITORAL DO PARANÁ. Distribuição do Eleitorado por Município/Zona. Disponível em: http://www.justicaeleitoral.jus.br/arquivos/tre-pr-elocadastro-eleitoral-eleitorado-ordenado-por-municipio

TRIBUNAL REGIONAL ELEITORAL DO PARANÁ. Estatísticas Eleitorais de 2014. Disponível em: $\quad$ http://www.tse.jus.br/eleicoes/estatisticas/estatisticas-candidaturas2014/copy of estatisticas-eleitorais-2014

TRIBUNAL REGIONAL ELEITORAL DO PARANÁ. Resultados de eleições municipais TRE-PR. Disponível em: $\quad$ http://www.tre-pr.jus.br/eleicoes/resultados/resultados-de-eleicoesmunicipais-tre-pr .

TRIBUNAL SUPERIOR ELEITORAL. Divulgação de Candidaturas e Contas Eleitorais 2016. Disponível em: http://www.tse.jus.br/eleicoes/eleicoes-2016/divulgacao-de-candidaturas-econtas-eleitorais 